\title{
COMPARISON BETWEEN TRAMADOL AND MEPERIDINE FOR TREATING SHIVERING IN PATIENTS UNDERGOING SURGERY UNDER SPINAL ANAESTHESIA
}

\author{
Acharya $S,{ }^{1}$ Dhakal $N^{2}$
}

${ }^{1}$ Department of Anaesthesia, ${ }^{2}$ Department of Community Medicine, Nepal Medical College Teaching Hospital, Attarkhel, Gokarneshwor-8, Kathmandu, Nepal.

\begin{abstract}
Shivering during regional anesthesia is a common problem and is distressing for patients with variety of complications. Therefore this study was conducted to compare the efficacy, potency, hemodynamic effects and side effects of tramadol with that of meperidine for the control of shivering during Spinal Anaesthesia. Sixty patients of ASA physical status I or II, aged 18 to 65 years, undergoing routine surgery under spinal anaesthesia and developed shivering intraoperatively were randomly allocated to receive $0.5 \mathrm{mg} / \mathrm{kg}$ meperidine intravenously (Group A, $\mathrm{n}=30$ ) or $0.5 \mathrm{mg} / \mathrm{kg}$ tramadol intravenously (Group B, $n=30$ ). Treatment that stopped shivering was considered to have been successful. The response rate was $100 \%$ in both the groups. The time that elapsed from treatment to the time shivering ceased was $5.37 \pm 2.20$ minutes for meperidine group and $5.87 \pm 2.92$ minutes for tramadol group ( $p>0.05$ ). The number of patients who assessed treatment efficacy as no, partial or marked improvement was 0, 2 and 28 for meperidine group and 0, 3 and 27 for tramadol group ( $>0.05$ ). Only two patients receiving meperidine developed pruritis and both the grops were similar in terms of Haemodynamic response. The result of this study concluded that tramadol $(0.5 \mathrm{mg} / \mathrm{kg})$ is as effective as meperidine $(0.5 \mathrm{mg} / \mathrm{kg})$ for treating post anaesthetic shivering with high safety profile.
\end{abstract}

\section{KEYWORDS}

Meperidine, Tramadol,

Postanaesthetic shivering, Spinal

Anaesthesia

\section{CORRESPONDING AUTHOR}

Dr Sulav Acharya

Lecturer,

Department of Anaesthesia,

Nepal Medical College Teaching Hospital,

Attarkhel, Gokarneshwor-8, Kathmandu, Nepal.

Email: sulav37@hotmail.com

Orcid ID: 0000-0002-8388-1450

DOI: https://doi.org/10.3126/nmcj.v22i1-2.30029 


\section{INTRODUCTION}

Postanesthetic shivering (PS) is distressing for the patients and may exacerbate postoperative pain, increase intracranial pressure, and induce cardiopulmonary complications. ${ }^{1-3}$ Although the etiology of PS is inadequately understood, various risk factors have been evaluated.-13 Among these, hypothermia, stress, uncontrolled pain, uninhibited spinalreflexes, and decreased sympathetic activity are frequently mentioned. .-13 $^{4}$ Regional anesthesia produces vasodilatation, which facilitates core-to-peripheral redistribution of heat and the cool periphery is warmed at the expense of the core compartment. Thus, hypothermia from epidural or spinal anesthesia results from redistribution of heat from the core to the periphery. ${ }^{14}$ Many physical methods like, active and passive warming systems, warming of inspired air, warming systems for IV fluids, blood and its products are tried in many studies, however these methods require use of specialised equipment, which is not economically feasible and practical in all clinical settings. ${ }^{15}$

Therefore pharmacological methods are used which are cost effective compared to physical methods. Many drugs have been used to treat PS, including meperidine, doxapram, tramadol, ketanserin, clonidine, propofol, physostigmine and nefopam..$^{4,5}$ Among these drugs, meperidine is often recommended for PS. ${ }^{4,5}$ Although its mechanism of action is not fully elucidated, much evidence suggests the drug's special antishivering activity is mediated by its k-opioid receptor activity. ${ }^{5,16,17}$ Meperidine is more effective in treating shivering than equi-analgesic doses of $\mu$-receptor agonists, such as morphine, fentanyl, alfentanil, and sufentanil. .6,18,19 $^{\text {Tramadol }}$ hydrochloride, a centrally-acting analgesic drug, is effective in the treatment of shivering after epidural anesthesia (EA) in parturients. ${ }^{20}$ In addition to a $\mu$-opioid agonist effect, it exerts a modulatory effect on central monoaminergic pathways, inhibiting the neuronal uptake of noradrenaline and serotonin..$^{21-24}$

Hence this study was conducted to compare the efficacy, potency, hemodynamic effects and side effects of tramadol with that of meperidine for the control of shivering during Spinal Anaesthesia.

\section{MATERIALS AND METHODS}

This study was carried out at Nepal Medical College Teaching Hospital after approval from Nepal Medical College Institutional Review Committee. Written informed consent was taken from all patients who participated in the study. Sixty patients of ASA physical status I or II, aged 18 to 65 years, undergoing routine surgery under spinal anaesthesia and developed shivering intraoperatively were included in the study. Patients with hyperthyroidism, cardiopulmonary or neuromuscular disease and patients contraindicated to meperidine, tramadol and spinal anaesthesia were excluded from the study. Shivering was graded with a scale similar to that validated by Crossley and Mahajan ${ }^{10}$ as follows.

$$
\begin{aligned}
0= & \text { No shivering } \\
1= & \text { Piloerection (no visible shivering) } \\
2= & \text { Muscular activity in only } 1 \text { mucle } \\
& \text { group } \\
3= & \begin{array}{l}
\text { Muscular activity in more than } 1 \\
\text { muscle group but not generalized } \\
\text { shivering }
\end{array} \\
4= & \text { Shivering involving the whole body }
\end{aligned}
$$

Only patients who developed Grade 3 or 4 shivering were included. The temperature of the operating room was maintained at 21 to 23 degree Celsius. Standard monitoring was used.

Spinal anaesthesia was given at lumbar vertebrae 3-4 or 4-5 interspace, with $0.5 \%$ bupivacaine heavy. All preloading fluids and drugs were used at room temperature. The administration of pre or intraoperative opioids was not permitted. Patients who shivered during surgery under spinal anaesthesia and requested antishivering treatment were randomly allocated to one of two groups for intravenous treatment: Group A $(n=30)$ received Meperidine $0.5 \mathrm{mg} / \mathrm{kg}$, and Group B $(n=30)$ received Tramadol hydrochloride $0.5 \mathrm{mg} /$ $\mathrm{kg}$. Patients did not know which drug was administered. The anaesthesiologist who were unaware of the patients group and treatment, measured the time elapsed from treatment to the time when shivering ceased. If shivering did not cease after $15 \mathrm{~min}$, the treatment was regarded as ineffective. Treatment efficacy was evaluated subjectively by the patients as no improvement, partial improvement, or marked improvement. Side effects, such as pruritus, somnolence (mildly sedated but easily aroused or heavily sedated), dizziness, nausea, vomiting, and respiratorydepression were recorded. Vital signs were measured before and $5 \mathrm{~min}$ after spinal anaesthesia, as well as $5 \mathrm{~min}$ after treatment. Statistical Analysis was performed using SPSS 16 software. $\mathrm{P}<0.05$ was considered statistically significant.

\section{RESULTS}

The two groups did not differ significantly with respect to age, gender, ASA physical status, base line heart rate(HR), systoli blood pressure(SBP) and diastolic blood pressure(DBP) Table 1. 
Table 1: Demographic profile and base line vitals.

\begin{tabular}{|lccc|}
\hline Variables & Meperidine & Tramadol & P value \\
\hline Age (yrs) & $36.97 \pm 14.01$ & $34.33 \pm 12.14$ & 0.44 \\
Sex (M/F) & $16 / 14$ & $20 / 10$ & 0.29 \\
ASA (I/II) & $21 / 9$ & $27 / 3$ & 0.50 \\
Baseline HR/min & $82.13 \pm 14.05$ & $83.20 \pm 15.56$ & 0.78 \\
Baseline SBP (mm Hg) & $128.33 \pm 13.29$ & $125.57 \pm 11.03$ & 0.38 \\
Baseline DBP (mm Hg) & $80.13 \pm 10.58$ & $78.40 \pm 8.61$ & 0.48 \\
\hline
\end{tabular}

Values are in mean \pm SD

Mean onset time of shivering after Spinal Anaesthesia in meperidine group was $12.63 \pm 7.17$ minutes and tramadol group was $13.70 \pm 9.75 \mathrm{~min}$ (Table 2).

\begin{tabular}{|lccc|}
\hline \multicolumn{4}{|c|}{ Table 2: Onset time of Shivering } \\
\hline $\begin{array}{l}\text { Onset time } \\
\text { of shivering } \\
\text { (min) }\end{array}$ & Mean & $\begin{array}{c}\text { Std. } \\
\text { Deviation }\end{array}$ & $\begin{array}{c}\mathbf{p} \\
\text { value }\end{array}$ \\
\hline Meperidine & 12.63 & 7.175 & 0.631 \\
Tramadol & 13.70 & 9.756 & \\
\hline
\end{tabular}

The Response rate (shivering cessation after treatment within 15 minutes) was 100\% in both the groups (Table 3).

\begin{tabular}{|lcc|}
\hline \multicolumn{3}{|c|}{ Table 3: Response Rate } \\
\hline Response & Yes & No \\
\hline Meperidine & $30(100 \%)$ & 0 \\
Tramadol & $30(100 \%)$ & 0 \\
\hline
\end{tabular}

The time that elapsed from treatment to the time shivering ceased was $5.37 \pm 2.20$ minutes for Meperidine group and $5.87 \pm 2.92$ minutes for Tramadol group (Table 4).

\section{Table 4: Time that elapsed from treatment to shivering cessation.}

\begin{tabular}{|lccc|}
$\begin{array}{l}\text { Treatment } \\
\text { to shivering } \\
\text { cessation (min) }\end{array}$ & Mean & $\begin{array}{c}\text { Std. } \\
\text { Deviation }\end{array}$ & $\begin{array}{c}\mathbf{p} \\
\text { value }\end{array}$ \\
\hline Meperidine & 5.37 & 2.205 & \\
Tramadol & 5.87 & 2.921 & 0.457 \\
\hline
\end{tabular}

The number of patients who assessed treatment efficacy as no, partial or marked improvement was 0,2 and 28 for Meperidine group and 0, 3 and 27 for Tramadol group which did not differ significantly (Table 5).

Table 5: Patient assessed treatment efficacy.

\begin{tabular}{|lccc|}
$\begin{array}{l}\text { Patient assessed } \\
\text { treatment efficacy }\end{array}$ & Marked & Partial & p value \\
\hline Meperidine & $28(93 \%)$ & $2(7 \%)$ & 0.64 \\
Tramadol & $27(90 \%)$ & $3(10 \%)$ & \\
\hline
\end{tabular}

Two patients treated with meperidine developed wheals, flare and itching in the skin around the vein being injected. Other side effects, such as nausea, vomiting, dizziness, somnolence and respiratory depression did not occur. The reaction faded itself within 10 minutes without any treatment. No any side effects occurred in patient treated with Tramadol (Table 6).

\section{Table 6: Comparison of side effects}

\begin{tabular}{|lccc|} 
Side effects & Yes & No & p value \\
\hline Meperidine & $2(7 \%)$ & $28(93 \%)$ & 0.49 \\
Tramadol & $0(0 \%)$ & $30(100 \%)$ & \\
\hline
\end{tabular}

In addition, the vital parameters such as heart rate and arterial blood pressure were not significantly different, 5 minutes after Spinal Anaesthesia and 5 minutes after treatment for shivering with Meperidine or Tramadol except in post treatment systolic blood pressure which showed significant difference between two groups (Table 7). 
Table 7: Vital parameters

\begin{tabular}{|lcccc|} 
& Group & Mean & Std. Deviation & p-value \\
\hline \multirow{2}{*}{ Post spinal HR(min) } & Meperidine & 76.73 & 11.169 & 0.682 \\
& Tramadol & 78.20 & 16.014 & \\
Post spinal SBP(mm Hg) & Meperidine & 112.60 & 11.128 & 0.360 \\
& Tramadol & 115.33 & 11.807 & \\
post spinal DBP(mm Hg) & Meperidine & 67.27 & 12.996 & 0.628 \\
& Tramadol & 68.77 & 10.766 & \\
Post treatment HR(min) & Meperidine & 74.70 & 9.326 & 0.569 \\
& Tramadol & 76.23 & 11.307 & \\
Post treatment SBP(mm Hg) & Meperidine & 113.20 & 9.810 & 0.013 \\
& Tramadol & 119.90 & 10.496 & \multirow{2}{*}{0.541} \\
\hline
\end{tabular}

\section{DISCUSSION}

Shivering during regional anesthesia is a common problem and up to $56.7 \%$ incidence of shivering during regional anesthesia has been reported. ${ }^{25,26}$ Among all the drugs Meperidine and Tramadol are found to be most effective to control shivering. Tramadol with less respiratory depression and sedation has been used in controlling shivering and hence is a safe drug for treatment of post anesthetic shivering. ${ }^{20}$ Pethidine is one of the most effective drugs for control of postanesthetic shivering and is widely used for the purpose. ${ }^{27}$ Hence in this study we have compared Tramadol, a newer synthetic opioid with Pethidine, which is the gold standard drug for treatment of postanaesthetic shivering, in search for more safe and efficacious drug.

In this study the two groups were similar in terms of age, sex, ASA physical status, base line heart rate, systolic and diastolic blood pressure and onset time of shivering after spinal anaesthesia. Therefore these groups were comparable.

Different doses of Tramadol from $0.2 \mathrm{mg} / \mathrm{kg}$ to $3 \mathrm{mg} / \mathrm{kg}$ were used to control postoperative shivering in different studies. ${ }^{27-29}$ Wrench et al $^{30}$ suggested that the minimal effective dose of meperidine for treating PS is approximately 0.35 $\mathrm{mg} / \mathrm{kg}$. In this study we used tramadol $0.5 \mathrm{mg} / \mathrm{kg}$ and meperidine $0.5 \mathrm{mg} / \mathrm{kg}$ which was effective in controlling shivering in $100 \%$ of patients in both the groups. The response rate ie, shivering ceased after treatment in a study conducted by Tsai et $a l^{31}$ was only $87 \%$ for tramadol group and $93 \%$ for meperidine group in similar dose as compared to our study.
In this study, the time taken for shivering cessation after treatment with Meperidine was $5.37 \pm 2.20$ minutes and with Tramadol was $5.87 \pm 2.92$ minutes which was statistically similar. Similar findings were reported in a study done by Tsai et al. ${ }^{31}$ Studies from Dhimar et $a l^{15}$ and Talakoub et $a^{32}$ showed that Tramadol is better than pethidine for controlling PS. Many studies have demonstrated the usefulness of tramadol in control of shivering, studies have also demonstrated that, tramodol is more effective in treatment of shivering when compared to other drug like Pethidine. ${ }^{28,32-35}$ In this study we found that tramadol is as effective as meperidine in treatment of PS.

In this study, two patients receiving meperidine developed wheals flare and itching in the skin around the vein being injected whearas patients receiving tramadol did not have any side effects. Disadvantages of meperidine treatment are the side effects of sedation and respiratory depression, which may be induced with previously administered opioids or anesthetics. In the study conducted by Tsai et $a l^{31}$ the incidence of somnolence in the group that received meperidine $(33 \%)$ was more frequent than in those who received tramadol (7\%) or amitriptyline (0\%). Pruritus, nausea, and vomiting were also important potential side effects but did not occur frequently with the dosage used. Because both tramadol and meperidine have similar shivering quenching effects, whereas tramadol has a decreased incidence of central depressive effects, they concluded that tramadol should be considered superior to meperidine for the treatment of shivering. 
The vital parameters were similar in both the groups except the post treatment systolic blood pressure. It was $113.20 \pm 9.81 \mathrm{mmHg}$ in meperidine group and $119.90 \pm 10.496 \mathrm{mmHg}$ in tramadol group. Though statistics showed significant change it is within normal range in both the groups. The result of this study indicates that tramadol $(0.5 \mathrm{mg} / \mathrm{kg})$ is as effective as meperidine $(0.5 \mathrm{mg} / \mathrm{kg})$ for treating post anaesthetic shivering with high safety profile.

\section{REFERENCES}

1. Guffin A, Girard D, Kaplan JA. Shivering following cardiac surgery: hemodynamic changes and reversal. J Cardiothorac Anesth 1987; 1: 24-8.

2. Ciofolo MJ, Clergue F, Devilliers C, Ben Ammar M, Viars P. Changes in ventilation, oxygen uptake, and carbon dioxide output during recovery from isoflurane anesthesia. Anesthesiol 1989; 70: $737-$ 41.

3. MacIntyre PE, Pavlin EG, Dwersteg JF. Effect of meperidine on oxygen consumption, carbon dioxide production and respiratory gas change in post-anesthesia shivering. Anesth Analg 1987; 66: 751-5.

4. Singh P, Dimitriou V, Mahajan RP, Crossley AW. Double-blind comparison between doxapram and pethidine in the treatment of postanaesthetic shivering. Br J Anaesth 1993; 71: 685- 8.

5. Kurz M, Belani KG, Sessler DI, Kurz A, Larson MD, Schroeder M, et al. Naloxone, meperidine, and shivering. Anesthesiol 1993; 79: 1193-201.

6. DeWitte J, Deloof T, DeVeylder J, Housmans PR. Tramadol inthe treatment of postanesthetic shivering. Acta Anaesthsiol Scand 1997; 41: 506 -10.

7. Joris J, Banache M, Bonnet F, Sessler DI, Lamy M. Clonidine and ketanserin both are effective treatment for postanesthetic shivering. Anesthesiol 1993; 79: 532-9.

8. Cheong KF, Low TC. Propofol and postanaesthetic shivering. Anaesthesia 1995; 50: $550-2$.

9. Horn EP, Standl T, Sessler DI, et al. Physostigmine prevents postanesthetic shivering as does meperidine or clonidine. Anesthesiol 1998; 88:108 -13 .

10. Crossley AWA, Mahajan RP. The intensity of postoperative shivering is unrelated to axillary temperature. Anaesth 1994; 49: 205-7.

11. SesslerDI, IsraelD, PozosRS, et al. Spontaneouspostanesthetic tremor does not resemble thermoregulatory shivering. Anesthesiology 1988; 68: 843-50.

12. Xiong J, Kurz A, Sessler DI, et al. Isoflurane produces marked and nonlinear decreases in the vasoconstriction and shivering thresholds. Anesthesiology 1996; 85: 240-5.

13. Farber NE, Poterack KA, Kampine JP, Schmeling WT. The effects of halothane, isoflurane, and enflurane on thermoregulatory responses in the neuraxis of cats. Anesthesiology 1994; 80: 879-91.

14. Reda S. Abdelrahman. Prevention of shivering during regional anaesthesia: Comparison of Midazolam, Midazolam plus ketamine, Tramadol, and Tramadol plus Ketamine. Life sci J 2012; 9: 1329.

15. Dhimar A A, Patel M G, Swadia V N. Tramadol for control of shivering(Comparison with Pethidine). Indian J Anaesth 2007; 51: 28-31.

16. Pauca AL, Savage RT, Simpson S, Roy RC. Effect of pethidine,fentanyl and morphine on post-operative shivering in man. Acta Anaesthesiol Scand 1984; 28 : 138-43.

17. Ikeda T, Kurz A, Sessler DI, Go J, Kurz M, Belani $\mathrm{K}$, et al. The effect of opioids on thermoregulatory responses in humans and the special antishivering action of meperidine. Ann NY Acad Sci 1997; 813: 792-8.

18. Wrench IJ, Cavill G, Ward JEH, Crossley AWA. Comparison between alfentanil, pethidine and placebo in the treatment of post-anaesthetic shivering. Br J Anaesth 1997; 79: 541-2.

19. Alfonsi P, Sessler DI, Du Manoir B, Levron JC, Moing JP, Chauvin M. The effects of meperidine and sufentanil on the shivering threshold in postoperative patients. Anesthesiol 1998; 89: 43-8.

20. Chan AM, Jacobus Ng KF, Tong EW, Jan G S K . Control of shivering under regional anesthesia in obstetric patients with tramadol. Can J Anaesth 1999; 46: 253-8.

21. Driessen B, Reimann W. Interaction of the central analgesic tramadol with the uptake and release of 5 -hydroytrytamine in the rat brain in vitro. $\mathrm{Br} J$ Pharmacol 1992; 105: 147-51.

22. Driessen B, Reimann W, Giertz H. Effects of the central analgesic tramadol on the uptake and release of noradrenaline and dopamine in vitro. $\mathrm{Br}$ J Pharmacol 1993; 108: 806-11.

23. Giusti P, Buriani A, Cima L, Lipartiti M. Effect of acute and chronic tramadol on [3H]-5-HT uptake in rat cortical synaptosomes. Br J Pharmacol 1997; 122: 302-6.

24. Raffa RB, Friderichs E, Reimann W, Shank RP, Codd EE, Vaught JL. Opioid and non-opioid components independently contribute to the mechanisms of action of tramadol, an atypical opioid analgesic. $J$ Pharmacol Exp Ther 1992; 260: 275-85.

25. Hong JY, Lee IH. Comparison of effects of intrathecal morphine and pethidine on shivering after Cesarean Delievery under combined spinal epidural anesthesia. Anesthesia 2005; 60: 1168-72.

26. Sagir O, Gulhas N, Toprak H, Yucel A, Begec Z, Ersoy O. Control of Shivering during regional anesthesia:Prophylactic ketamine and Granisetron. Acta Anaesthesiol Scand 2007; 51: 44-9. 
27. Mohta M, Kumari N, Tyagi A, Sethi A.K, Agarwal D, Singh M. Tramadol for prevention of postanaesthetic shivering: a randomised doubleblind comparison with pethidine. Anaesthesia 2009; 64: 141-6.

28. Sajedi P, Khalili G, Kyhanifard L. Minimum effective dose of Tramadol in the treatment of postanesthetic shivering. JRMS 2008; 13: 75-9.

29. Trekova NA, Buniatian AA, Zolicheva NIu. Tramadol hydrochloride in the treatment of postoperative shivering. Anesteziol Reanimatol 2004; 5: 86-9.

30. Wrench IJ, Singh P, Dennis AR, Mahajan RP, Crossley AW. The minimum effective doses of pethidine and doxapram in the treatment of postanaesthetic shivering. Anaesthesia 1997;52:32-6.

31. Yu-Chuan Tsai, Koung-Shing Chu. A comparison of Tramadol, Amitriptyline and Meperidine for postepidural Anesthetic shivering in parturients. Anesth Analg 2001; 93: 1288-92.

32. Reihanak Talakoub, Shahrokh Noorimeshkati. Tramadol versus pethidine in the treatment of shivering in cesarean section. J Res Med Sci 2006; 11: 151-5.

33. Javaherforoosh F, Akhondzadeh R, Aein KB, Olapour A, Samimi M. Effects of tramadol on shivering post spinal anesthesia in elective cesarean section. Pak J Med Sci 2009; 25: 12-7.

34. Matsukawa T, Sessler DI, Christensen R, Ozaki M, Schroeder M. Heat flow and distribution during epidural anesthesia. Anesthesiology 1995; 83: 9617.

35. Mathews S, Mulla Al, Varghese PK., Radim K, Mumtaz S. Postanaesthetic shivering - a new look at Tramadol. Anaesthesia 2002; 57: 394-8. 